\title{
«Era aventura pura» \\ Géneros cinematográficos, circuitos de exhibición \\ e imaginarios en la Buenos Aires \\ de las décadas de 1940 y 1950
}

Cecilia Gil Mariño, Alejandro Kelly Hopfenblatt \& Sonia Sasiain

Recibido: 30.10.2020 — Aceptado: 15.11.2020

\section{Titre / Title/ Titolo}

«C'etait une pure aventure». Genres cinématographiques, circuits d'exposition et imaginaires à Buenos Aires dans les années 1940 et 1950

«It was pure adventure». Film genres, exhibition circuits and imaginaries in 1940's and 1950's Buenos Aires

«Era pura avventura». Generi cinematografici, circuiti espositivi e immaginari a Buenos Aires negli anni Quaranta e Cinquanta del Novecento

\section{Resumen / Résumé / Abstract / Riassunto}

A partir de la incorporación de la historia oral, la historiografía del cine y el entretenimiento masivo ha complejizado sus preceptos y ha generado nuevas preguntas. Dentro de ellas, el interrogante sobre el gusto y el consumo se ha vuelto central para reformular nociones como la popularidad y el éxito de los filmes o la relación del cine con la sociedad. El presente artículo ahonda en estas temáticas a partir de la centralidad que tuvieron las estructuras genéricas del cine clásico. Para ello se retoman las propuestas de Rick Altman acerca de su carácter dinámico y los trabajos de Annette Kuhn sobre la memoria cultural para estudiar los públicos de cine de Buenos Aires de la década de 1940 y 1950. A partir de un conjunto de entrevistas a adultos mayores, se indaga en su impacto tanto sobre sus hábitos de consumo como sobre sus modos de relacionarse con su ambiente.

Depuis l'incorporation de l'histoire orale, l'historiographie du cinéma et des divertissements de masse a rendu ses préceptes plus complexes et elle a proposé de nouvelles questions. Parmi lesquelles, la question du goût et de la consommation est devenue fondamental pour reformuler des notions comme la popularité et le succès des filmes, ou la relation entre le cinéma et la société. Le présent article aborde ces thèmes à partir de la centralité qu'avaient les structures génériques du cinéma classique. À cette fin, elle reprend les propositions de Rick Altman sur son caractère dyna- mique et le travail d'Annette Kuhn sur la mémoire culturelle pour étudier le public des filmes de Buenos Aires dans les années 1940 et 1950. À partir d'une série d'entretiens avec des personnes âgées, on explore leur impact sur leurs habitudes de consommation et leurs modes de relation avec leur environnement.

The incorporation of oral history methodology into film and entertainment historiography has brought more complex and original perspectives. Among them, inquiries on taste and consumption are leading to a reformulation of notions such as popularity and success and to new frameworks to study the relationship between film and society. This paper delves into these subjects by focusing on the role played by genre narratives in classical cinema. We take into account Rick Altman's proposal about the dynamic character of genres and Annette Kuhn's works on cultural memory in order to look into Buenos Aires' film spectators in the 1940s and 1950s. By taking into consideration a group of interviews with senior citizens, we study film genres' impact on their consumer habits and their relations with their environment.

Con l'incorporazione della storia orale, la storiografia del cinema e dello spettacolo di massa ha reso più complessi i suoi precetti e ha generato nuove domande. La questione del gusto e del consumo è diventata centrale per riformulare nozioni come la popolarità e il successo dei film, o il rapporto tra cinema e società. Il presente articolo approfondisce questi temi a partire dalla centralità delle strutture di genere nel cinema classico. A tal fine, riprende le proposte di Rick Altman sul suo carattere dinamico e la riflessione di Annette Kuhn sulla memoria culturale per studiare il pubblico cinematografico di Buenos Aires negli anni quaranta e cinquanta. Sulla base di una serie di interviste con spettatori anziani, esplora l'impatto dei generi cinematografici sulle loro abitudini di consumo e sul loro modo di relazionarsi con l'ambiente. 


\section{Palabras clave / Mots-clé / Key words IParole chiave}

Públicos cinematográficos, cine clásico, géneros cinematográficos, modernidad, imaginarios sociales.

Public cinématographique, cinéma classique, genres cinématographiques, modernité, imaginaires sociaux.

Movie audiences, classical cinema, film genres, modernity, social imaginaries.

Pubblico cinematografico, cinema classico, generi cinematografici, modernità, immaginari sociali.

Nuestro escape en ese mundo de seis manzanas era el cine, el cine Aesca. En aquel entonces la supremacía la tenía el cine estadounidense, nos contagiábamos y creíamos en esas películas. Luego de ver una película como Tres lanceros de Bengala, una exaltación colonialista, volviamos transformados en soldados de la legión extranjera, entusiastas con eso.

Juan Carlos (nacido en 1933)

Juan Carlos nació en el barrio de Saavedra en el norte de la ciudad de Buenos Aires en 1933, por lo que señala que su marca cinéfila es el haber nacido junto al cine sonoro argentino. Aún más, al haber crecido cerca de los Estudios Lumiton, una de las principales compañías productoras nacionales de los años treinta y cuarenta, considera que esta proximidad atravesó sus vivencias, sus deseos y su pasión por el cine durante toda su vida. Cuenta que él vivía en una frontera; en aquellos años la Avenida General Paz, que divide a la capital argentina de sus suburbios, no existía, por lo que a una cuadra de su casa ya era todo campo, una zona de extensiones de quintas. Atravesar esa frontera era el pasatiempo predilecto familiar; el gran entretenimiento, recuerda, era salir a caminar. Así que su primer recuerdo del cine es el edificio de los Estudios Lumiton y la esquina donde estaba el restaurante La cuchara de palo, al cual iban a comer todas las estrellas de esa época.
El testimonio de Juan Carlos se introduce dentro de un estudio que busca recuperar dentro de la historia del cine argentino el espacio de los públicos y la experiencia de ir al cine. Esta perspectiva se enmarca dentro de los debates que marcaron al campo de los estudios de cine a nivel global en las últimas décadas que han descentrado la mirada de las películas y la dimensión de la producción para poder pensar en las audiencias y los circuitos de exhibición. En este sentido se han renovado las preguntas y se han marcado nuevos rumbos de análisis, lo que permitió el surgimiento de enfoques que complejizaron la relación de estos artefactos culturales con discursos y prácticas culturales, así como también con la dinámica de una economía del entretenimiento transnacional y transmedial, y con la esfera de la sociedad en su conjunto. Entender a las audiencias como objeto ha abierto nuevas posibilidades para pensar al cine en tanto experiencia cinematográfica.

Esta nueva historia del cine (o New Cinema History) ${ }^{1}$ incorpora también dimensiones institucionales, sociales y culturales del consumo y circulación del cine (Maltby, Biltereyst y Meers, 2011). En esta historia del cine «escrita desde abajo» se explora a los espectadores y a la materialidad de sus prácticas, sus formas de involucramiento, sus rutinas y sus representaciones. De esta manera, la historia oral y la revisión de archivos de memorias y documentos personales se tornan fundamentales (Stokes y Jones, 2017). En esta misma dirección, se inserta la propuesta de Anette Kuhn (2017) quien indaga sobre la memoria cultural de los sujetos y sus imbricaciones con el cine.

Estas nuevas perspectivas suponen la consolidación de nuevas herramientas que sirven no sólo para construir objetos de investigación novedosos sino también para revisitar terrenos ya transitados bajo una nueva luz. Un espacio con gran productividad dentro de ello es el que respecta a los géneros cinematográficos. El estudio de los mismos cobró un nuevo impulso en el siglo

Richard Maltby (2006) ha propuesto el concepto de New Cinema History para englobar los trabajos de historia del cine que en los últimos años han desplazado la mirada hacia la dimensión social y comercial del cine con propuestas focalizadas en la exhibición, distribución y recepción. 
XXI de la mano de análisis renovadores como los trabajos de Rick Altman (2000) y Jason Mittel (2004) que plantean pensar las formas mutantes bajo las cuales la categoría genérica opera culturalmente, es decir, de qué manera estos textos son apropiados por sus usuarios de maneras distintas. Así, el género se presenta como un conjunto de expectativas compartidas y una faceta dinámica que se sintetiza bajo la idea de un abordaje sintáctico-semántico-pragmático.

Con este concepto, Altman destacó que «las películas de Hollywood están diseñadas para beneficiarse de múltiples afiliaciones» (198). Es así que plantear el cruce entre los estudios sobre los géneros con la historia oral permite focalizar justamente en uno de los espacios más cambiantes que es la apropiación por parte de los públicos y el lugar que esta brinda a las estructuras genéricas. Si bien los enfoques sobre estas se han centrado usualmente en el terreno de la producción y la comercialización cinematográfica, el consumo ha jugado un rol central en su configuración a lo largo de la historia.

Resulta interesante entonces pensar el lugar que ocuparon los géneros en el contexto de las prácticas audiovisuales de los espectadores de cine en los años de apogeo del modelo clásico de producción basado en ellos. Un claro ejemplo de ello es el estudio de Pierluigi Ercole, Daniela Treveri Gennari y Catherine O'Rawe (2017), quienes exploraron las relaciones de los espectadores italianos con los sistemas de géneros y estrellas en la década de 1950. De este modo demostraron la relevancia de insertar los géneros dentro de la New Cinema History ya que cumplían roles diversos, desde sistemas de pertenencia e identidades colectivas a mediaciones en las relaciones sociales y familiares.

El presente artículo propone ahondar en estos interrogantes a partir de la centralidad que tuvieron las estructuras genéricas del cine clásico en los espectadores que asistieron a las salas comerciales en Buenos Aires en las décadas de 1940 y 1950. Se indagará en su impacto tanto sobre sus consumos y sus comportamientos sociales como sobre los circuitos de exhibición de la época. En este sentido, los géneros conformaron una forma de acercarse al cine al mismo tiempo que proveyeron de he- rramientas que mediaron y dieron sentido a la cambiante vida moderna que se vivía en los grandes centros urbanos.

Para el desarrollo de este artículo hemos recuperado los testimonios brindados en 21 entrevistas en profundidad, realizadas entre 2017 y 2020, a adultos mayores nacidos entre 1924 y 1941 que fueron espectadores de cine durante la década de 1940 y 1950 en la ciudad de Buenos Aires. El muestreo teórico se realizó siguiendo la búsqueda de la máxima variabilidad en términos del origen social familiar. Los entrevistados fueron contactados siguiendo distintas estrategias como visitas a geriátricos y viviendas de ancianos, o consultas entre contactos del equipo de investigación. De este conjunto, catorce entrevistas se hicieron a mujeres y siete a hombres. Sus orígenes sociales son variados, incluyendo a personas de orígenes humildes, de clase trabajadora, pero también a algunos sujetos de clase media, profesionales y/o empleados en servicios. El guion de las entrevistas abordó cuestiones como los primeros recuerdos de salidas al cine, las rutinas asociadas al cine, las salas frecuentadas, el tipo de películas que se elegía, los actores y celebridades, la lectura de revistas de cine, entre otras. $^{2}$

\section{Ampliar la ciudad}

A finales de 1941, la compañía productora Establecimientos Filmadores Argentinos (EFA) publicaba en la revista Film, dirigida a los exhibidores y distribuidores cinematográficos, un anuncio a doble página de su plan de producción para 1942. De las nueve cintas presentadas allí, cuatro tenían título -Escuela nocturna, La novela del joven pobre, La mucama millonaria y Malambo-. Las otras en cambio eran «una comedia sentimental», dos «comedias cómicas», «un film de conjunto» y una «gran come-

\footnotetext{
Las entrevistas que conforman las fuentes de este artículo son parte de un proyecto de investigación mayor que se encuentra en curso actualmente con sede en el Instituto de Artes del Espectáculo «Raúl H. Castagnino» de la Universidad de Buenos Aires, titulado «Una historia de los públicos en Buenos Aires (1933-1955)». El mismo propone en primer lugar la construcción de nuevas fuentes a partir del relevamiento de las carteleras cinematográficas, la realización de una cartografía de las salas y sus transformaciones, y la conformación de un archivo de historia oral de los públicos cinematográficos porteños.
} 
dia musical». Con mayor o menor descripción en cada caso, se planteaba así un escenario similar al que configuraban las diferentes empresas productoras nacionales en esos años, con una factoría construida alrededor de los sistemas de estrellas y de géneros. ${ }^{3}$

En gran medida, el campo cinematográfico argentino se había configurado siguiendo los parámetros establecidos por el sistema de estudios de Hollywood. Desde la década de 1920 Buenos Aires se había consolidado como una plaza de gran interés para los distribuidores norteamericanos y se había convertido en uno de sus principales mercados de exportación del cine norteamericano. Lisa Jarvinen (2012) indica que un reporte interno de United Artists en 1935 señalaba que Argentina era, después del Reino Unido, el principal mercado de exportación para el cine de Hollywood y que en 1934 el comercio fílmico hacia el país había llegado a un estimado de 15 millones de pies de película.

La importancia de Argentina para el mercado norteamericano implicaba asimismo una marcada presencia de sus cintas en los circuitos fílmicos locales. De alrededor de 4900 películas publicitadas en la cartelera cinematográfica del diario La Nación entre 1933 y 1938, 3500 eran de origen estadounidense. El resto se repartían entre producciones locales, algunas latinoamericanas y de países europeos como España, Francia, Alemania o Italia. ${ }^{4}$

Bajo esta impronta, tanto la producción como los modos de exhibición y distribución se habían conformado en torno a los parámetros que provenían de Hollywood. En este sentido, los dos sistemas sobre los que se conformaba el sistema de los grandes estudios -las estrellas y los géneros- se transformaron prontamente en los ejes vertebrales que dieron forma a la oferta fílmica en la ciudad. Esto se daba a lo largo de todo el circuito exhibidor, desde las salas céntricas hasta las barriales.

Para comprender la inserción de esta modalidad en la vida de los espectadores debe considerarse la relación del cine con las dinámicas de cambio que vivía la ciudad en esos años. La dimensión urbana de Buenos Aires a

Film, 25 de diciembre de 1941, nº 1337.

Datos de elaboración propia a partir de las carteleras cinematográficas publicadas en el diario La Nación entre 1933 y 1938. mediados de 1930 era extendida y baja, con mayor densidad de construcciones en el centro. La expansión de edificios en altura y de salas se intensificó en esos años a partir de la ampliación de la red de transporte subterráneo y del colectivo, que comenzó a circular en las zonas no conectadas por los medios de locomoción tradicionales. Las avenidas se ensancharon para permitir el tránsito del parque automotor en constante aumento. Todos estos cambios permitieron la circulación más fluida de publicidad y de películas entre los diversos circuitos de distribución y exhibición cinematográfica.

Las salas para el espectáculo se distribuyeron hacia la periferia siguiendo los nuevos nodos de circulación generados por la ampliación del recorrido de la red de transporte. Muchas de esas salas, ubicadas sobre avenidas o calles de zonas comerciales, se construyeron en el nivel de la planta baja de nuevos edificios de oficina o de vivienda, lo cual evidencia una convergencia de intereses cinematográficos e inmobiliarios.

En este marco, para la década de 1940, el cine era el espectáculo dominante y más frecuentado por la población porteña. Existían alrededor de 200 salas en la ciudad, incluyendo los palacios del centro, donde se estrenaban las películas nuevas, y los circuitos más modestos de las salas barriales, que recibían esos títulos algunas semanas después. Los boletos de ingreso a las salas eran relativamente económicos, por lo cual las familias de clase media podían permitirse asistir con mucha frecuencia, una o dos veces por semana.

De este modo, el cine era uno de los principales consumos culturales de los habitantes de la ciudad. Manuel, quien pasó toda su infancia en Parque Patricios, cuenta que los cines de su barrio tenían una pizarra afuera con las películas que daban en la semana y específicamente ese día, y así la gente se enteraba de la programación. También recuerda que una sala como el Urquiza, de mayor categoría dentro del barrio, tenía una marquesina como las del centro de la ciudad con los títulos de la semana. Por su parte, María Simone, quien nació en 1935 en el barrio de La Boca, también señala que se enteraban gracias al mismo cine o bien por el programa que les entregaban en la función porque anunciaba la 
programación. Al igual que Manuel también resalta el «boca en boca» del barrio.

Acerca de la programación ofrecida por los cines que no fueran del barrio, María Simone recuerda que se enteraban por el diario, ya sea que lo haya comprado su familia o cualquier otro vecino. En su caso, también señala que muchas veces no sabían los títulos de las películas pero las identificaban por algún género o estrella en particular, con sugerencias como «vamos a ver las de Tita Merello». Del otro lado de la ciudad, hacia el norte de Buenos Aires, Juan Carlos en Saavedra y Nilda, nacida en 1929 en el barrio de Núñez también resaltan la importancia de estas pizarras, carteles y programas. Nilda cuenta que como iban todas las semanas, ya sabían lo que iban a dar la próxima y que muchas veces elegían por sus actores y actrices predilectos como Barbara Stanwyck, en su caso.

Las carteleras cinematográficas de los diarios y revistas se organizaron con estas nuevas coordenadas en las que las salas actuaban, según señala Annette Kuhn, como centros magnéticos que atraían a los espectadores por su variada oferta. La circulación de cintas y la información sobre ellas, así como su programación, estaban organizadas, en gran parte, por el sistema de estudios, especializados en la producción de determinados géneros. Esto implicó, a lo largo del período, una especialización de la prensa en el modo de presentar los filmes, así como de los espectadores que aprendieron a decodificar reiteraciones narrativas y temáticas con los rótulos de las carteleras o de los programas. ${ }^{5}$

La crítica y la publicidad generaban el deseo de ver determinada película solo porque pertenecía a un género específico o porque estaba garantizada por determinado estudio especializado en ese género. Como hemos visto en el ejemplo de EFA, citado al comienzo, no hacía falta más indicación que el tipo de película para ya comenzar a promocionarla. De un modo similar, es común encontrar en los testimonios de los entrevistados sus relatos de infancia en los que la ida al cine era

\footnotetext{
Asimismo, como señala Cecilia Gil Mariño, se multiplicaron también kioscos de revistas y receptores de radio en los hogares que colaboraban en el delineamiento de nuevos hábitos de un policonsumidor que era espectador-oyente-lector y que deseaba ver y escuchar en las salas a las estrellas que ya conocía por la radio o por publicaciones populares como Antena y Radiolandia.
}

marcada por la presencia de los seriales. Era común en la cartelera de las salas de barrio que hubiera un día para niños, habitualmente la matiné del domingo con variedades, y un largo que incluía un juego de dos episodios en inglés de un serial de doce, que los obligaba a ir todas las semanas para no perderse ninguno.

El lugar de los géneros dentro de las estrategias de exhibición era reconocido por los propios empresarios del sector. Un caso interesante, por ejemplo, es el del exhibidor Guillermo McInnes quien, en un número especial de Heraldo del cinematografista de 1942 daba su opinión sobre la situación del mercado cinematográfico en una nota titulada: «Trato de orientar al público en mis salas». ${ }^{6}$ Entre otros conceptos, señalaba que «He observado que el público ya no busca estrellas solamente sino dirección y argumento, prefiriendo, a mi entender, el género comedia, como Soñar no cuesta nada y Los martes, orquídeass. ${ }^{7}$ De este modo, a lo largo de la década del cuarenta las estructuras genéricas que servían de base para el sistema de producción ocuparon también un lugar central en las estrategias comerciales.

Los distintos géneros se insertaban así en programas diferenciados. El cine de aventuras es en este sentido uno de los ejemplos más claros, ya que sus películas podían ser tanto grandes estrenos de las principales salas como títulos intercambiables de los programas continuados de los cines de barrio. Los testimonios masculinos de infancia resaltan la importancia de las películas de aventuras y de «convoys» como les llamaban a los filmes de cowboys en la época. Juan Carlos también recuerda que le gustaba acompañar a su madre a ver las románticas.

Por su parte, las mujeres rescatan la categoría «romántica», aunque, al igual que aventuras, sirve para englobar diversas propuestas. Nilda, por ejemplo, recuerda de este modo sus vivencias de adolescente asistiendo enamorada a ver títulos como Rebeca, una mujer inolvidable (Rebecca, Alfred Hitchcok, 1940) y Cumbres borrascosas (Wuthering Heights, William Wyler, 1939). La diversidad

El Heraldo del cinematografista era la principal publicación dedicada al gremio exhibidor y en ella se discutían las políticas del sector y las estrategias comerciales que se iban desarrollando.

Heraldo del Cinematografista, número extraordinario, julio de 1942: s/d 


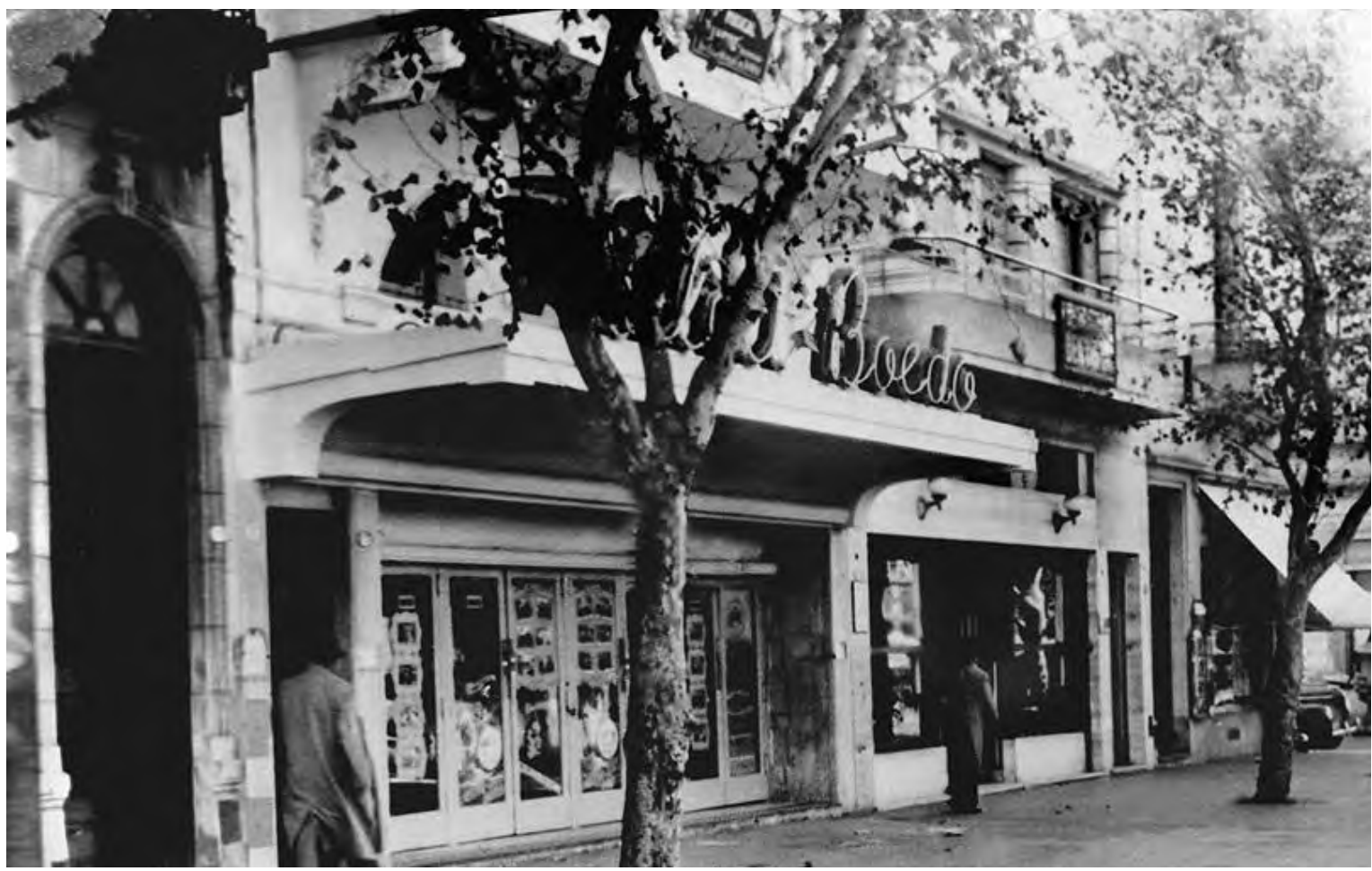

Frente del Cine Select Boedo

de películas y las formas en que eran recibidas da cuenta nuevamente del carácter cambiante que señala Altman (2000) con relación a los géneros. Como señala Silvia Dibeltulo (2020), estas definiciones alternativas eran mediadas por las emociones que suscitaban, y que suscitan todavía actualmente en el recuerdo, estas películas, ya que no solamente eran relatos a los que se asistía sino que configuraban formas de ver el mundo.

\section{El cine de mujeres}

\footnotetext{
- Me gustaba más Rita Hayworth, viste que tuvieran otro tipo de encanto... Estas eran medio zonzas (risas).

- ¿Rita Hayworth, por qué te gustaba?

- No sé Rita Hayworth era muy interesante, era linda, bailaba bien, porque bailaba muy bien, este, no sé, me gustaba, me parecía piola.
}

(Graciela, nacida en 1935)
Miriam Hansen (1999) plantea que uno de los principales motivos por los que el cine clásico de Hollywood ocupó un lugar dominante en el mercado cinematográfico global fue a través de la conformación de un imaginario global compartido donde espectadores de lugares remotos del planeta podían pasar a formar parte del mundo moderno. A partir de esta 'modernidad vernácula', Hansen propone considerar la experiencia del espectador frente a estas películas desde una perspectiva sensorial, en donde el cine actuaba como un dispositivo de difusión de imágenes que eran articuladas por los públicos con sus realidades circundantes.

La propuesta de Hansen puede pensarse en consonancia con las formulaciones de Anthony Giddens, quien plantea que la modernidad se caracteriza por ser un proceso de cambio social donde el tiempo y el espacio se homogeneizan a nivel global y producen así una experiencia de desanclaje para el sujeto. Así las prácticas y las relaciones sociales se rearticulan y los medios de comunicación juegan un rol central en la forma en que 
los individuos se posicionan frente a este mundo. En este sentido señala que:

Existe una conexión directa (aunque dialéctica) entre las tendencias globalizadoras de la modernidad y lo que llamaré la transformación de la intimidad en el contexto de la vida cotidiana; que la transformación de la intimidad debe analizarse en términos de la construcción de mecanismos de fiabilidad; y que en tales circunstancias, las relaciones personales de fiabilidad están íntimamente ligadas a una situación en la que la construcción del yo se convierte en un proyecto reflexivo. (110)

El cine clásico, y especialmente el cine de Hollywood, tuvieron así un rol de mediación de la experiencia moderna para los espectadores de Buenos Aires, y el sistema de géneros y estrellas que permitía organizarlo fue central en ello. Un terreno particular en que se puede encontrar esta vivencia es en la experiencia de las espectadoras. Para la mujer porteña, como para gran cantidad de mujeres alrededor del mundo, el cine permitió ensanchar su mundo y asomarse a novedosos espacios. Al respecto, una crónica de Biyina Klappenbach de La Nación señalaba, por ejemplo: « (...) el cine es también la moda. Allí está todo lo más novedoso en modas femeninas: sombreros, peinados audaces, vestidos, 'maquillages', modales y hasta modas masculinas y buenos mozos.... ${ }^{8}$

En la memoria de las mujeres el cine es un espacio para soñar y fantasear con películas (y vidas) románticas. Como señala Alicia, los «días de damas se exhibían siempre películas románticas, con parejas famosas». Para las espectadoras, el cine era una posibilidad de transportarse a otro mundo e imaginar vidas románticas y la sala era un espacio de libertad para soñar. Pero al terminar la función, retornaban rápidamente los mecanismos de contención social a través de la institución familiar: las mujeres casi no iban solas al cine, en el sentido de que se consideraban salidas familiares, y en cualquier caso, debían volver a la casa cumpliendo los horarios establecidos, o bien las iba a buscar algún familiar.

\footnotetext{
8 La Nación, agosto de 1944, por Biyina Klappenbach. Carpeta de recortes, Archivo Museo del Cine Pablo Ducrós Hicken.
}

Si para los hombres y los niños el cine de aventuras suponía un género del cual podían apropiarse, en torno a las mujeres se desarrolló un espacio que excedía numerosas formulaciones de la teoría de los géneros cinematográficos: el cine de mujeres. ${ }^{9}$ Este término ha sido extensamente estudiado en su relación con el melodrama, especialmente desde una perspectiva feminista por autoras como Molly Haskell. A partir de estos trabajos, Altman (2000) propone al cine de mujeres o woman's film como un paradigma de aquellos ciclos de producción que, a partir de su apropiación por parte del público, se transforman en un género cinematográfico.

Es interesante considerar cómo desde distintos espacios de la cultura se concebía este territorio. En las páginas de la revista Claridad también se podían leer las críticas de intelectuales socialistas a la identificación del público femenino con este cine de mujeres:

En las más, todo se reduce a unas nociones de bordado, corte y confección, unos cuantos arpegios en el piano y un poco de literatura tropical, y, junto con el diploma de maestra, toda esta pseudocultura va a parar al mismo extremo: el anzuelo para "pescar" marido. La disputa del macho en las jovenzuelas de clase media es toda una tragedia doméstica con sus derivados patológicos: neurastenia, romanticismo misticismo. "Novela semanal", cine y posturas a la Joan Crawford o Greta Garbo. (...) El "ideal" de hombre de las muchachas de la clase media es el de un tipo a la Valentino, acicalado, dulzón y que posea un título universitario de "doctor" (aunque sea procurador) o un "alto empleo". (...) La solterona beata, desarreglada, la vestida de luto y la "que Dios no le dio hijos ni marido pero el Diablo sobrinos" para educar y criar, ha desaparecido para dejar lugar a la solterona pintada, maquillada, cinematografera, callejera, amiga del copetín, de las peñas artísticas y que, por su gran experiencia (que dan los años), por su "cancha", como dicen aquí, triunfa en la difícil pesca del hombre, sobre la inexperta, tilinga y lozana belleza de las jovencitas"10

Durante el período que se extiende desde 1930 hasta 1944 no se observa que haya un día fijo para la renovación de las carteleras. Dado que muchas personas iban con frecuencia a la misma sala, durante la semana, los programas variaban para satisfacer a esos espectadores asiduos.

${ }^{10}$ Claridad, noviembre de 1933 (149) $\mathrm{N}^{\circ} 271$, s/d. La revista se presentaba como tribuna de la izquierda bajo el título de «Claridad: Revista de arte, crítica y letras. Tribuna del pensamiento izquierdista». 
En las primeras líneas de la cita se critica el «bovarismo cinematográfico» que podían desarrollar las mujeres solteras en busca de marido. En esta crítica hay una doble impugnación tanto del género como del sistema de representación cinematográfico de Hollywood. Por un lado, hay una crítica al aspecto comercial que el socialismo atribuía a las películas hollywoodenses vehiculizado a través de la cultura masiva transmitida a través de formatos estandarizados como la «novela semanal» y del sistema de estrellas necesario para establecerlo. Por otro, la cuestión del efecto patológico que el cine producía en las mujeres consideradas «enfermizas» o nerviosas y, por lo tanto, más proclives a transformarse en consumidoras del maquillaje y de las diversiones masivas. En este último punto, la crítica se acercaba a las posturas más conservadoras que veían de manera negativa la presencia ociosa de las mujeres en el espacio público.

El cine de mujeres, más allá de su amplitud genérica, suponía para las espectadoras un terreno donde depositar sus inquietudes y de donde aprender formas de comportamiento social y romántico. Alicia, por ejemplo, recuerda que las parejas muchas veces usaban las últimas filas del cine para «poder hacerse los arrumacos, que por ahí en la calle no lo hacían porque no era costumbre. No es costumbre como hoy, que uno ve a los chicos besarse, aún los mocosos de 14 o 15 años, como actores de cine». Coca, que nació en 1929 y vivió durante su niñez en el barrio de Belgrano, también recuerda el carácter transgresor de la salida al cine en relación con la sexualidad. Además de recortar a escondidas fotos de actrices y actores, era ella quien decidía a qué películas asistir con su madre. Para eso, consultaba antes con sus compañeras de escuela cómo era cada filme, y luego le contaba a su mamá lo que quería que supiera: «Si en la película se besaban, no lo contaba, porque sino mi papá no me dejaba ir»».

Graciela también recuerda recortar las fotos de sus «novios cinematográficos»:

La posibilidad de fantasear, a esa edad era importantísimo. Sigue siendo, porque te digo que la fantasía no se pierde. Incluso me acuerdo que veraneamos en Córdoba con esta amiga y cada una tenía una foto (risas) que jugábamos que eran nuestros maridos, semejantes grandotas, hoy en día inadmisible.

De este modo, el cine de mujeres no es solamente un modo de denominar un tipo de películas, sino, como reconstruyen las entrevistadas, era un terreno simbólico en torno al cual se configuraba una forma de vida social, familiar y afectiva. El género cinematográfico se transformaba así en un mediador y moldeador de la experiencia moderna para las espectadoras porteñas de los años cuarenta.

\section{Pura aventura}

El cine clásico no sólo permitía a los espectadores y a las espectadoras asomarse al mundo moderno, sino que también abría la posibilidad de otros universos posibles. En este sentido, el desanclaje que propone Giddens (1990) llevaba a veces a la conformación del sensorio compartido de la modernidad que plantea Hansen (1999), pero en otras ocasiones el universo imaginario que se configuraba tenía niveles mayores de distancia con el mundo real. Como señala Juan Carlos en la cita al inicio del artículo, entrar a una película de aventuras podía devolver a los niños a las calles convertidos en soldados de la Legión Extranjera.

Arjun Appadurai (1991) destaca en este sentido el rol disruptivo del cine como fuente para la imaginación social, asociado a la conformación de prácticas y de identidades sociales no siempre congruentes con el contexto socio-político de pertenencia de los espectadores. El cine permitió así el acceso a tramas, personajes, narrativas y escenarios que invitaban a los espectadores ensanchar el repertorio para la elaboración imaginaria de vidas posibles. Podemos pensar así en la idea de heterotopía que rescata Annette Kuhn (2004) como ese 'otro mundo' que abre el cine, un terreno lejano y ajeno al espectador que es al mismo tiempo fácilmente localizable en los relatos.

Desde el campo de los espectadores esta vivencia implicaba un pacto espectatorial necesario para que 
opere la fórmula genérica. ${ }^{11}$ Entre los entrevistados existen testimonios de la manera en que se involucraban en la ficción y que hasta los varones adultos se entregaban totalmente al espectáculo al poner en suspenso su incredulidad como espectador. Élida recuerda por ejemplo «la euforia que había en las salas, se salían de las butacas para alentar a los personajes, el público gritaba, se posesionaba con la historia. Fue inolvidable cuando fui a ver con mi novio Rebeca y Lo que el viento se llevór.

Además, son numerosos los relatos de la participación del público en el aliento al héroe o heroína del filme con gritos, palmadas o zapateos en el piso. Podemos pensar en este sentido en la propuesta de Altman quien señala que el género realiza ciertas operaciones a las que denomina encrucijadas (206). Éstas llevan a lo que denomina placer genérico, pero el mismo debe emanar no de la película sino de la posición que asumen los espectadores frente a ella. En este sentido señala el detalle de que los géneros predilectos suelen ser aquellos que apelan a las emociones, que plantean estructuras in crescendo que permiten al espectador elegir y experimentar desvíos de la norma. Aunque haya luego un regreso a las normas, el deleite del camino alternativo ya es una experiencia digna de ser vivida, un place genérico que se presenta como alternativa a las normas culturales.

El cine de aventuras vuelve a ser aquí el principal terreno donde se desarrollaba esta dinámica. Los testimonios de los espectadores cinematográficos presentan puntos de identificación en los entrevistados con el género de aventuras cuando relatan que iban al cine para autoconocerse, subjetivarse, y como sostiene Kuhn, vivir una experiencia que les permitiera salir a lo desconocido y ampliar los límites de sus recorridos urbanos. Esta idea se resume principalmente en los testimonios masculinos, que vivían a través de estos filmes el ingreso a lo desconocido.

En esta lógica, el testimonio de Mario presenta claramente esta idea. Al preguntarle por su experiencia en el

En nuestro medio, abundan las anécdotas acerca del modo en que los espectadores se involucraban aun desde el periodo del circo criollo con las escenas que representaban injusticias buscando repararlas al atacar a los actores que hacían de policías corruptos. cine recuerda que le emocionaba porque «aprendes de países, costumbres y formas de vida. África, por ejemplo, me gustaba. Siempre me gustó África, en libros y en películas» y recuerda en esta sintonía haber disfrutado de Tarzán, con Johnny Weissmüller, y Mogambo, con Clark Gable. África, como símbolo del exotismo y el ingreso a mundos remotos para los espectadores occidentales, condensaba así el desanclaje que el cine de aventuras permitía a un joven adolescente en un cine porteño en esos años.

Sin embargo, como señala Altman, no era sólo un proceso intelectual de aprendizaje el que llevaba a los espectadores a relacionarse con estos géneros. Era fundamentalmente lo vivencial y lo emocional que hacía que la experiencia trascendiera las fórmulas y convenciones del género. Jorge, nacido en 1939, resalta en su testimonio que el cine «era aventura pura, porque no sólo había películas de cowboys, sino que era aventura pura. Errol Flynn, con eso te digo todo, trabajaba muy bien. Era aventura pura». La triple repetición de la idea de 'aventura pura' resalta así un concepto que excedía al conocimiento de la trama o al aprendizaje sobre África. Si el cine de mujeres permitía al público femenino construir un terreno donde vivenciar la libertad de la vida moderna, los hombres parecen haber encontrado una experiencia similar en este espacio que los llevaba a lo desconocido.

\section{Conclusiones}

En 2006 el escritor y dramaturgo argentino Edgardo Cozarinsky publicó Palacios plebeyos, un libro homenaje a las salas de cine y la experiencia de ser espectador en aquellos grandes edificios que se constituían como templos del cinematógrafo. Dividido en tres secciones el libro se adentraba primero en una mirada histórica y celebratoria de esos espacios, para luego indagar en el aprendizaje sentimental y erótico que se vivía a su interior. La tercera sección del libro se alejaba de esa mirada y bajo el título «El caso de las sonrisas póstumas» presentaba un cuento policial donde se cruzaba la 
mitología del séptimo arte con la nostalgia de la vivencia de los espectadores de cine de antaño. Poblado de guiños cinéfilos, el relato retomaba numerosos elementos del género policial para abordar el caso de un grupo de ancianos que recibían un «relámpago de placer» para luego morir con imágenes cinematográficas «grabadas en la retina».

Si bien esta sección parecería ser discordante con las anteriores, su inserción le permitía a Cozarinsky traducir lo expuesto previamente en el libro a partir de una organización narrativa ligada a un género altamente codificado. Con una breve mención al universo policial, los detectives y las mujeres fatales, el autor transmitía a través de los personajes del cuento el impacto de la experiencia de ir al cine y al mismo tiempo daba cuenta de la centralidad de las estructuras genéricas en la organización de esa vivencia y de su recuerdo. Como los protagonistas del relato, los espectadores entrevistados fueron marcados por esa vivencia dentro de la sala, y al igual que para el autor, los géneros cinematográficos se transformaron en referentes ineludibles en su forma de configurar y entender el mundo.

Los géneros fueron marcos de referencia fundamental tanto para la comercialización y la exhibición como para los modos en que los espectadores se posicionaban frente a los filmes. Con universos claramente reconocibles, estrellas identificadas estrechamente con ellos y temáticas recurrentes que establecían un pacto implícito con los espectadores, las películas se valían de estas estructuras para orientar la práctica de ir al cine. Así, los géneros constituían un elemento importante para la elección de los filmes al mismo tiempo que, en los imaginarios de los entrevistados y entrevistadas, la categoría de género era aprehendida a partir de algún aspecto del mismo, ya sea por las emociones comúnmente provocadas, las estrellas a las que se los asociaba, o sus narrativas.

De este modo, se podían colocar en una misma categorías filmes muy diferentes pero que en el boca en boca del barrio construían un sentido común y una experiencia colectiva. Rick Altman plantea que el espectador de géneros, al reconocerse como tal, se integra a sí mismo a un grupo, real o imaginario, una comunidad genérica y constelada. En este sentido, la importancia de los géneros no se limitaba solamente a la estrategia del exhibidor o la vivencia individual del espectador. Los géneros permitían integrarse a un mundo y hacer de la ida al cine una vivencia colectiva.

Es necesario así recuperar nuevamente las propuestas de Annette Kuhn quien señala que los recuerdos sobre la experiencia de ir al cine tienden a recuperar los espacios, las compañías y las rutinas, en el marco de un relato colectivo que da cuenta de una práctica compartida con otros y por tanto, estrechamente ligada a la sociabilidad. Dentro de una nueva historia del cine que considere a los públicos y su experiencia cinematográfica, resulta fundamental considerar entonces el lugar de los géneros cinematográficos en esta dinámica compartida de la vida social.

Podemos volver así a la cita de Juan Carlos al inicio y considerar el uso de la primera persona del plural en su recuerdo. El cine de aventuras unía a su grupo de amigos, los hacía partícipes de una misma experiencia urbana y una vivencia compartida dentro de la sala, los asomaba a mundos desconocidos y los convertía, momentáneamente, en otras personas. $\mathrm{Y}$ así Buenos Aires en los años cuarenta se poblaba, gracias a estas propuestas narrativas del cine industrial, de vampiresas, soldados, corsarios y princesas que transitaban sus calles modernas como personajes de un universo ficcional compartido globalmente.

\section{Bibliografía}

Altman, Rick. Los géneros cinematográficos. Barcelona: Paidós, 2000.

Appadurai, Arjum. Modernity at large. Cultural dimensions of globalization. Minneapolis: University of Minnesota Press, 1991.

Cozarinsky, Edgardo. Palacios plebeyos. Buenos Aires: Sudamericana, 2006.

Dibeltulo Silvia. «Reconstructing historical film genre consumption in post-war Italy», ponencia presenta- 
da en el Webinar Film Audience Movements and Migrations: Across Borders and Screens, Oxford, Septiembre 2020.

Giddens, Anthony. Las consecuencias de la modernidad. Madrid: Alianza, 1990.

Gil Mariño, Cecilia. El mercado del deseo: Tango, cine y cultura de masas en la Argentina de los '30. Buenos Aires: Teseo, 2015.

Hansen, Miriam. «The Mass Production of the Senses: Classical Cinema as Vernacular Modernism». Modernism/Modernity, 6(2), 1999, pp. 59-77.

Jarvinen, Lisa. The Rise of Spanish-Language Filmmaking: Out from Hollywood's Shadow, 1929-1939. New Brunswick and London: Rutgers University Press, 2012.

Kuhn, Annette. «Heterotopia, heterocronia: place and time in cinema memory». London, Screen 45; 2, Summer, 2004, pp. 106- 114.

- «Memories of cinemagoing and film experience: An introduction». Memory Studies, 10 (1), 2017, pp. 3-16.

Maltby, Richard. «On the Prospect of Writing Cinema History from Below». Tidjschrift voor mediageschiedenis, 9 (2), 2006, pp. 74-96.

Maltby, Richard; Biltereyst, Daniël, and Meers, Philippe. Explorations in New Cinema History: Approaches and Case Studies. Routledge, 2011.

Mittell, Jason. Genre and Television. From Cop Shows to Cartoons in American Culture. London and New York: Routledge, 2004.

Stokes, Melvyn and Jones, Matthew. «Windows on the World: Memories of European Cinema in 1960s Britain». Memory Studies, 10 (1), 2017, pp. 78-90.

Ercole, Pierluigi; Treveri Gennari, Daniela, and O'Rawe, Catherine. «Mapping Cinema Memories: Emotional Geographies of Cinemagoing in Rome in the 1950s». Memory Studies, 10 (1), 2017, pp. 63-77.

\section{Fuentes}

\section{Entrevistas}

Clauso, Nilda. Entrevista individual, 11 de octubre de 2017.

Domínguez Neira, Graciela. Entrevista individual, 27 de diciembre de 2019.

García, Coca. Entrevista individual, 20 de enero de 2020

Leguizamón, Jorge. Entrevista individual, 13 de enero de 2020.

Marchetti, Élida. Entrevistas realizada por Daniela Merlano en 2009 en el marco del curso de Historia de los medios, de la Universidad Nacional de Quilmes, cátedra Daniel Dabenes.

Portas, Juan Carlos. Entrevista individual, 20 de octubre de 2018.

Rodríguez, Alicia. Entrevista individual, 17 de diciembre de 2019.

Simone, María. Entrevista individual, 25 de enero de 2018.

Telias, Mario. Entrevista individual, 13 de enero de 2020

Vila, Manuel. Entrevista individual, 28 de agosto de 2018.

\section{Publicaciones periódicas}

Claridad, noviembre de 1933 (149) n²71, s/d.

Heraldo del Cinematografista, número extraordinario, julio de 1942: s/d

Film, 25 de diciembre de 1941, $\mathrm{n}^{\circ} 1337$, s/d.

La Nación, agosto de 1944, por Biyina Klappenbach. Carpeta de recortes, Archivo Museo del Cine Pablo Ducrós Hicken 
